\title{
ESTÁDIO DE MATURAÇÃO PARA O PERÍODO IDEAL DE COLHEITA DE MAÇÃS 'DAIANE' DESTINADAS À ARMAZENAGEM ${ }^{1}$
}

\author{
MAYARA CRISTIANA STANGER ${ }^{2}$, LUIZ CARLOS ARGENTA ${ }^{3}$, \\ CRISTIANO ANDRÉ STEFFENS ${ }^{4}$, CASSANDRO VIDAL TALAMINI DO AMARANTE ${ }^{5}$
}

RESUMO - Este trabalho foi realizado com o objetivo de identificar índices de maturação para o ponto ideal de colheita, de maçãs 'Daiane', destinadas a longos períodos de armazenamento. Maçãs foram colhidas semanalmente, em dois pomares comerciais, no período de 113 a 149 dias após a plena floração (DAPF), e armazenadas por 180 ou 240 dias a $0,7^{\circ} \mathrm{C}$, em atmosfera controlada. Medidas do estádio de maturação e da qualidade das maçãs foram realizadas um dia após a colheita e após a armazenagem. Atributos da aparência (cor vermelha) e sabor (relação açúcar/acidez) indicaram que a qualidade de maçãs 'Daiane', na colheita, é máxima quando colhidas 149 DAPF. No entanto, medidas da firmeza da polpa e da qualidade sensorial, realizadas após a armazenagem, indicaram que o período ideal de colheita de maçãs 'Daiane', destinadas a longos períodos de armazenagem, não deve estender-se além dos 136 DAPF. Maçãs 'Daiane' devem ser colhidas a partir de 121 DAPF para que mais da metade dos frutos tenham mais de $75 \%$ da superfície avermelhada. Desta maneira, o período ideal de colheita de maçãs 'Daiane', destinadas a longos períodos de armazenagem, ocorreu entre 121 e 136 DAPF no pomar 1, e entre 129 e 136 DAPF no pomar 2. No período ideal de colheita (121 a 136 DAPF), maçãs 'Daiane' apresentaram, um dia após a colheita, firmeza de 67 a $74 \mathrm{~N}, \mathrm{SS}$ de 11,5 a $13 \%$, AT de $0,26 \%$ a 0,34\%, índice de amido de 4,6 a 7,9 e índice de cor de fundo da epiderme de 2,6 a 4,0 .

Termos para indexação: Ponto de colheita, pós-colheita, distúrbios fisiológicos, qualidade, sabor.

\section{MATURITY INDICES FOR THE OPTIMUM HARVEST DATES OF "DAIANE"APPLE DESIGNATED TO STORAGE}

\begin{abstract}
The study was carried out to identify the maturity indices for the optimum harvest dates of 'Daiane' apples designated to long-term storage. Apples were harvested weekly from 113 to 149 days after full bloom (DAFB), and stored for 180 or 240 days at $0.7^{\circ} \mathrm{C}$ under controlled atmosphere. Maturity and quality were assessed one day after harvest and after storage. Fruit quality, based on skin red color was highest when harvested lately, 149 DAFB. However, measures of firmness and taste after long-term CA storage indicated that the ideal harvest period for 'Daiane' apples should not exceed 136 DAFB. 'Daiane' apples should be picked at 121 DAFB to achieve more than half of the fruit with over $75 \%$ skin surface with red color. Therefore, the optimum harvest period for 'Daiane' apples designated to long-term storage is between 121 and 136 DAFB at orchard 1, and between 129 and 136 DAFB at orchard 2. At optimum harvest period (121-136 DAFB) 'Daiane' apple had, one day after harvest, firmness of 67-74 N, SS from 11.5 to 13\%, TA of $0.26 \%-0.34 \%$, starch index from 4.6 to 7.9 and background color index between 2.6 and 4.0 .
\end{abstract}

Index terms: Harvest date, postharvest, physiological disorders, quality, taste.

'(Traballho 169-13). Recebido em: 13-05-2013. Aceito para publicação em: 02-10-2013.

2Doutoranda em Produção Vegetal, CAV/UDESC, Lages-SC. E-mail: mayara.stanger@gmail.com

${ }^{3}$ Eng. Agr., D.Sc., Pesq. da Epagri, Cx. P. 591, CEP 89500-000, Caçador-SC. E-mail: argenta@epagri.sc.gov.br

${ }^{4}$ Eng.. Agr., Dr., Professor do Depto. de Agronomia, CAV/UDESC, Lages-SC. E-mail: steffens@cav.udesc.br

${ }^{5}$ Eng. Agr., Ph.D., Professor do Depto. de Agronomia, CAV/UDESC, Lages-SC. E-mail: amarante@cav.udesc.br 


\section{INTRODUÇÃO}

'Daiane' é uma nova cultivar de macieira, resultante do cruzamento entre 'Gala' ( + ) e 'Princesa' $(\widehat{)})$, que produz frutos semelhantes à 'Gala' quanto à aparência, sabor e aroma (DENARDI; CAMILO, 1998). Estes autores e Fioravanço et al. (2011) alegam que o contínuo aumento da produção de maçãs 'Daiane', nos Estados do RS e SC, desde seu lançamento em 1992, deve-se especialmente a fatores de produção: 1) as plantas possuem resistência à doença Mancha Foliar de Glomerela, o que possibilita redução expressiva dos custos de produção e dos riscos de contaminação dos trabalhadores e do meio ambiente em relação àqueles com macieiras 'Gala'; 2) O período de colheita comercial dos frutos concentra-se entre aqueles das cultivares Gala e Fuji, as quais representam mais de $90 \%$ da produção nacional, favorecendo o escalonamento da colheita; e 3) as plantas possuem menor exigência ao frio hibernal para a superação da dormência e maior produtividade em relação à 'Gala'.

O estádio de maturação no momento da colheita é um dos fatores que mais afetam a qualidade na colheita e após a armazenagem de maçãs (WATKINS, 2003; WATKINS et al., 2005). A qualidade de maçãs aumenta durante sua maturação pelo aumento do tamanho, da coloração, do aroma e do sabor, e, por isso, podem ser colhidas em estádios avançados de maturação, mas antes de iniciar a senescência, quando destinadas ao mercado imediato, alegam os mencionados autores. Por outro lado, a qualidade de maçãs destinadas à armazenagem por longos períodos pode ser afetada negativamente, tanto pela antecipação quanto pelo retardamento excessivo da colheita. Maçãs colhidas precocemente são mais suscetíveis ao desenvolvimento de distúrbios, como murchamento, escaldadura superficial e "bitter pit", enquanto maçãs colhidas tardiamente são mais suscetíveis ao desenvolvimento de podridões, danos por $\mathrm{CO}_{2}$, danos mecânicos e distúrbios relacionados à senescência, tais como polpa amarronzada, polpa farinácea e rachadura (WATKINS, 2003; WATKINS et al., 2005; DE CASTRO et al., 2007). Adicionalmente, maçãs podem ser insípidas, especialmente pelo baixo teor de açúcares e pela baixa produção de compostos aromáticos, quando colhidas precocemente, ou apresentarem qualidade sensorial desagradável devido à perda de crocância e de suculência, e relação açúcar/acidez excessivamente alta, quando colhidas tardiamente (PLOTTO et al., 1995; LITTLE; HOLMES, 2000; WATKINS et al., 2005).

Dezenas de indicadores da evolução de maturação de maçãs têm sido propostas, incluindo medidas bioquímicas, fisiológicas, morfológicas, físicas, sensoriais e da aparência (WATKINS, 2003). De acordo com Watkins (2003), a produção de etileno é o principal indicador fisiológico do estádio de maturação de maçãs, por ser o hormônio que regula a maturação e a senescência de frutos climatéricos. No entanto, o aumento acentuado, autocatalítico, da produção de etileno nos frutos ligados à planta não coincide com o período de colheita comercial, hortícola, para muitas cultivares, como Golden Delicious e Fuji (ARGENTA, 1993), além de ser significativamente influenciada pela região e pelo ano de produção, época de cultivo e variabilidade na população de frutos (WATKINS, 2003; ARGENTA et al., 1995). Devido a estas limitações, a taxa de produção de etileno deve ser utilizada em conjunto com outros índices de maturação para predizer o estádio ideal para a colheita.

$\mathrm{Na}$ prática, os indicadores de maturação de maçãs que mais se relacionam com o ponto ideal de colheita comercial para máxima qualidade sensorial ou alto potencial de armazenagem são a firmeza de polpa, o índice de amido, o teor de sólidos solúveis e a cor de fundo da epiderme (LITTLE; HOLMES, 2000; WATKINS, 2003). Esses indicadores de maturação também são os mais usados pelos fruticultores pela simplicidade, rapidez e baixo custo das análises (ARGENTA et al., 2010). Adicionalmente, o percentual de cobertura das maçãs com cor vermelha é levado em consideração para determinar o início da colheita, por afetar significativamente a aparência e seu valor comercial (WATKINS, 2003; BRASIL, 2006; ARGENTA et al., 2010).

Medidas fisiológicas e físico-químicas de maçãs 'Daiane', correspondentes ao período ideal de colheita comercial e para a máxima qualidade após a armazenagem, ainda não foram estabelecidas. A identificação do ponto ideal de colheita de maçãs 'Daiane', por medidas da maturação, tem-se tornado prioridade de pesquisa, à medida que se atingem novos patamares de produção a cada ano.

Este trabalho foi realizado com o objetivo de identificar índices de maturação para o período ideal de colheita de maçãs 'Daiane' destinadas a longos períodos de armazenamento refrigerado em atmosfera controlada.

\section{MATERIAL E MÉTODOS}

Maçãs 'Daiane' foram colhidas em dois pomares comerciais, localizados no município de Fraiburgo-SC $\left(27^{\circ} 01^{\prime} \mathrm{S}\right.$ e $50^{\circ} 55^{\prime} \mathrm{O}$, com altitude 
entre 950-1.000 m), na safra de 2010/2011. O pomar MKM9 era constituído por plantas com cinco anos de idade, sobre porta-enxerto Marubakaido e filtro M-9, espaçadas em $0,7 \mathrm{~m}$ na linha e 4,25 $\mathrm{m}$ entre linhas. O pomar M9 era constituído por plantas com oito anos de idade, sobre porta-enxerto M-9, espaçadas em 1,0 m na linha e 3,5 m entre linhas. Em ambos os pomares, foram aplicadas as mesmas práticas de cultivo e manejo preconizadas pelo sistema de produção integrada de macieiras, exceto a aplicação do inibidor da síntese de etileno aminoetoxivinilglicina(AVG; ReTain ${ }^{\mathrm{TM}}, 124 \mathrm{mg}$ de i.a. $\mathrm{L}^{-1}$ ), 100 dias após a plena floração (DAPF), realizada apenas no pomar M9.

Os tratamentos consistiram em colheitas realizadas semanalmente, durante seis semanas, aos 113; 121; 129; 136; 143 e 149 DAPF. Logo após cada colheita, foram preparadas, em laboratório, três amostras homogêneas de 50 frutos, de forma casualizada para cada pomar, sendo uma amostra para a análise dos atributos de maturação realizada no dia seguinte à colheita $\mathrm{e}$ as demais foram destinadas à armazenagem por 180 e 240 dias. Apenas frutos sem defeitos morfológicos e livres de danos (mecânicos, por doenças e insetos) foram selecionados.

Os frutos foram armazenados em câmara comercial sob atmosfera controlada (AC), com pressões parciais de $1,8 \mathrm{kPa}$ de $\mathrm{O}_{2}$ e 2,0 $\mathrm{kPa}$ de $\mathrm{CO}_{2}$, temperatura de $0,7 \pm 0,5^{\circ} \mathrm{C}$ e umidade relativa do ar de $92 \pm 4 \%$. Após o armazenamento, os frutos foram mantidos sob atmosfera do ar (AA) a $23 \pm 0,3^{\circ} \mathrm{C}$ e umidade relativa de $68 \pm 6 \%$, por sete dias, antes de serem analisados. Analisaram-se 50 frutos de cada pomar e data de colheita, para cada período de armazenagem.

Cada fruto foi considerado como uma repetição para as análises da intensidade de cor vermelha e índice de amido na colheita, cor de fundo e firmeza de polpa na colheita e após a armazenagem e da incidência, e severidade de distúrbios fisiológicos e patológicos após a armazenagem. Os teores de sólidos solúveis (SS), a acidez titulável (AT) e as taxas respiratória e de produção de etileno foram analisados na colheita e após a armazenagem, utilizando quatro subamostras de sete frutos, correspondentes a quatro repetições por tratamento.

A intensidade de cor vermelha foi estimada visualmente, considerando a porcentagem de área coberta com a coloração vermelha, relativa à superfície total do fruto. A cor de fundo também foi estimada visualmente, atribuindo-se notas de 1 a 5 , conforme catálogo de escalas de cores desenvolvido para maçãs 'Gala' (ARGENTA et al., 2010). O índice de amido foi avaliado utilizando a escala de 1 a 9 , na qual o índice 1 (secção transversal da polpa corada pelo complexo iodo-amido) indica alto teor de amido e fruto imaturo, e o índice 9 (secção transversal da polpa não corada pelo complexo iodo-amido) indica teor de amido próximo a zero e fruto amadurecido. A firmeza da polpa (N) foi medida com a utilização de um penetrômetro eletrônico motorizado, com ponteira de $11 \mathrm{~mm}$ (Güss, África do Sul), em dois pontos opostos, na região equatorial de cada fruto, após a remoção da epiderme. Os teores de SS e a AT foram determinados no suco preparado com espremedor centrífugo (Plastaket Mgf, Estados Unidos). O teor de SS (\%) foi medido usando refratômetro digital com compensação automática de temperatura (Atago, Japão). A AT (\% de ácido málico) foi determinada pela titulação de $10 \mathrm{~mL}$ de suco, diluído em $20 \mathrm{~mL}$ de água destilada, $\mathrm{com} \mathrm{NaOH}$ $0,1 \mathrm{~N}$ até $\mathrm{pH} 8,2$, usando-se titulador automático (Radiometer, França).

As avaliações das taxas respiratória e de produção de etileno foram feitas em quatro amostras de frutos, usando um sistema de fluxo contínuo. Amostras de frutos $( \pm 1000 \mathrm{~g})$ foram colocadas em jarras de $4 \mathrm{~L}$, supridas com ar comprimido, livre de etileno, a $100 \mathrm{~mL} \mathrm{~min}^{-1}$, e mantidas a $23 \pm 0,3{ }^{\circ} \mathrm{C}$ durante $12 \mathrm{~h}$, para o equilíbrio da temperatura. $\mathrm{O}$ ar efluente foi analisado para as concentrações de $\mathrm{CO}_{2}$ e de etileno, por um cromatógrafo gasoso (Shimadzu 14B, Japão), equipado com um metanizador, dois detectores de ionização de chama, uma coluna de aço inoxidável com 1,0 m de comprimento e 2,0 $\mathrm{mm}$ de diâmetro interno (para $\mathrm{CO}_{2}$ ) e uma coluna de vidro com 1,6 m de comprimento e 3,2 milímetros de diâmetro interno(para etileno). Ambas as colunas continham Poropak Q 80 a 100 mesh como fase estacionária. As temperaturas para forno, detectores, metanizador e injetor foram fixadas em $45 ; 120 ; 300$ e $110^{\circ} \mathrm{C}$, respectivamente. Os fluxos de gás de $\mathrm{N}_{2}, \mathrm{H}_{2}$ e ar foram de $70 ; 30$ e $300 \mathrm{~mL} \mathrm{~min}^{-1}$, respectivamente, para as análises de etileno e $\mathrm{CO}_{2}$.

A incidência de frutos com sintomas de rachadura senescente foi avaliada, atribuindose escores 1 e 2, para ausência e presença, respectivamente. Para podridões, foram atribuídos escores 1: para ausência; e 2 e 3: para uma ou duas lesões com somatório de diâmetro(s) inferior a 1 $\mathrm{cm}$ e superior a $1 \mathrm{~cm}$ de diâmetro, respectivamente.

O distúrbio de escurecimento pistilar, na região do córtex, foi analisado visualmente pela severidade dos sintomas, caracterizado pela epiderme e/ou córtex com coloração amarronzada. Considerando que a severidade desse distúrbio diminui longitudinalmente a partir da região distal ao 
pedúnculo, seu grau de severidade foi determinado pela análise em três cortes transversais do fruto, conforme segue: corte inferior, na região dos lóbulos, na cavidade pistilar; corte mediano, no terço inferior do fruto, entre a margem inferior da cavidade carpelar e o corte inferior; corte superior, no meio do fruto e da cavidade carpelar. Os escores de severidade desse distúrbio foram: 1: ausência de sintoma; 2: córtex com coloração amarronzada presente apenas na secção transversal do corte inferior; 3 : córtex com coloração amarronzada presente nas secções transversais dos cortes inferior e mediano; 4: epiderme e córtex com cloração amarronzada presente nas secções transversais dos três cortes.

O distúrbio de escurecimento carpelar (também denominado de coração amarronzado), que se limita aos tecidos de origem carpelar (na medula), foi analisado visualmente pela severidade do sintoma, conforme a percentagem da secção transversal da região carpelar com coloração amarronzada: 1 : sem dano; 2) 1 a $10 \%$; 3) $11 \%$ a $50 \%$; e 4) mais de $50 \%$. Esse sintoma foi analisado apenas no corte superior, descrito para a avaliação do escurecimento pistilar.

Duas amostras de 10 frutos de cada data de colheita, do pomar MKM9, foram analisadas quanto à qualidade sensorial, após 180 e 240 dias sob AC a $0,7^{\circ} \mathrm{C}$, mais 7 dias sob AA a $23^{\circ} \mathrm{C}$. A análise sensorial foi realizada pelo método de ordenação, conforme descrito por Chaves e Sproesser (2005), com pequena modificação. Apresentou-se a cada julgador, em cada oportunidade de análise, uma bandeja com seis amostras de maçãs, correspondendo aos seis tratamentos (datas de colheita) em cada época de análise. Cada amostra correspondeu a 1/4 de uma maçã cortada na forma de cunha. As cunhas de frutos foram cortadas e descascadas imediatamente antes da análise sensorial. Solicitou-se aos julgadores que analisassem sensorialmente as amostras, ordenassemnas da melhor para a pior, de acordo com a qualidade da textura e do sabor, e a seguir conferissem uma nota da qualidade global (textura e sabor), seguindo a seguinte escala: 1 (ruim); 2 (regular); 3 (bom); 4 (muito bom), e 5 (excelente). Duas ou mais amostras poderiam receber a mesma nota, caso o julgador não as distinguisse quanto à textura e sabor

Foi utilizado o delineamento experimental inteiramente casualizado, com 50 repetições (cada repetição correspondendo a um fruto) por tratamento (data de colheita) e época de análise, exceto para as análises de SS, AT, etileno e respiração, sendo utilizadas quatro repetições de sete frutos por tratamento. Apenas para os dados de qualidade global (textura e sabor) foi utilizado o delineamento em blocos ao acaso, sendo o bloco correspondente ao julgador (com um total de 20 julgadores). Os dados foram submetidos à análise da variância (ANOVA), utilizando o programa SAS. Os efeitos de tratamento (data de colheita) foram analisados pelo teste de Tukey $(\mathrm{p}<0,05)$. Os efeitos das datas de colheita sobre a firmeza de polpa foram ajustados através da análise de regressão, para determinar a taxa de perda de firmeza de polpa.

\section{RESULTADOS E DISCUSSÃO}

A taxa respiratória de maçãs 'Daiane' não mudou significativamente entre 113 e 136 DAPF no pomar MKM9, nem entre 113 e 143 DAPF no pomar M9 (Figura 1). Pequeno aumento da taxa respiratória ocorreu entre 129 e 149 DAPF no pomar MKM9 e entre 143 e 149 DAPF no pomar M9. Esses resultados indicam que maçãs 'Daiane' estavam em estádio correspondente ao mínimo respiratório até 129 DAPF no pomar MKM9, e até 143 DAPF no pomar M9. A taxa respiratória de maçãs é máxima no período de divisão celular, durante as primeiras semanas após a fecundação, e diminui 2 a 3 vezes ao longo de seu crescimento, para atingir um mínimo antes do início da maturação hortícola (comercial) (WATKINS, 2003).

A maturação de maçãs 'Daiane' caracterizouse pelo aumento significativo da produção de etileno a partir de $136 \mathrm{DAPF}$, em ambos os pomares (Figura 1). Estudos indicam que o período ideal de colheita de maçãs destinadas à armazenagem por longos períodos ocorre no estádio em que a respiração é mínima, e antes do aumento acentuado da produção de etileno (ARGENTA; MONDARDO, 1994; WATKINS, 2003). Por isso, os dados referentes à produção de etileno indicam que o período ideal de colheita de maçãs 'Daiane', destinadas a longos períodos de armazenagem, não deveria estender-se além de 136 DAPF, para ambos os pomares. A maturação de maçãs normalmente é antecipada quando produzida sobre o porta-enxerto anão M-9 em relação àquelas sobre porta-enxerto vigoroso Marubakaido (BARDEN; MARINI, 1992; FALLAHI, 2012). Ao contrário, a maturação de maçãs é retardada pelo tratamento com inibidor da síntese de etileno, AVG (STEFFENS et al., 2006; AMARANTE et al., 2010). Isso justifica por que o aumento acentuado da produção de etileno ocorreu na mesma semana em ambos os pomares, apesar de um pomar ser sobre porta-enxerto anão e o outro sobre porta-enxerto vigoroso. Aparentemente, o efeito antecipador da maturação do porta-enxerto anão M-9 foi anulado pelo efeito retardador da maturação do AVG.

Durante a maturação de maçãs 'Daiane', 
houve redução da firmeza da polpa e da AT, associada à contínua degradação do amido (aumento do índice de amido), amarelecimento da epiderme e aumento da intensidade de coloração vermelha e do teor de SS (Figuras 2 e 3), em ambos os pomares, conforme esperado e já descrito para muitas outras cultivares de maçãs (LITTLE; HOLMES, 2000; WATKINS, 2003; WATKINS et al., 2005; STEFFENS et al., 2006). Pequeno aumento da taxa de degradação do amido e da taxa de amarelecimento da epiderme coincidiu com o aumento da produção de etileno, a partir de 136 DAPF, no pomar M9. No entanto, muitas das alterações relativas à maturação e à qualidade dos frutos, inclusive a degradação do amido, iniciaram antes de se detectar aumento significativo, climatérico, da respiração e da produção de etileno (Figura 1), semelhantemente ao descrito para as cultivares Gala, Golden Delicious e Fuji (ARGENTA, 1993). O fato de a degradação do amido ter iniciado antes do aumento acentuado da taxa de evolução de etileno, indica que esse processo, possivelmente, seja induzido por baixas alterações da concentração endógena de etileno, não detectadas pelo método de análise usado neste estudo. A degradação do amido é considerada um evento dependente do etileno, conforme demonstrado para maçãs tratadas com o inibidor da ação do etileno, 1-metilciclopropeno (WATKINS et al., 2010). O índice de amido é uma técnica simples e rápida, e, por apresentar aumento coincidente, não significa que essa alteração química, tipicamente associada à maturação dos frutos, não tenha sido induzida pelo etileno endógeno. A degradação do amido é considerada um evento dependente do etileno, conforme demonstrado para maçãs tratadas com o inibidor da ação do etileno, 1-metilciclopropeno (WATKINS et al., 2010). O fato de a degradação do amido iniciar-se antes do aumento significativo da evolução do etileno do fruto indica que esse processo, possivelmente, seja induzido por baixas alterações da concentração endógena de etileno, não detectadas pelo método de análise usado neste estudo. $\mathrm{O}$ fato de o índice de amido ser determinado de forma simples e rápida, e frequentemente aumentar antes ou juntamente ao aumento acentuado da evolução de etileno pelos frutos, torna-o um dos mais importantes indicadores do início da maturação e do ponto de colheita de maçãs em nível comercial (ARGENTA et al., 2010).

Taxas de perda de firmeza diária ou semanal são indicativos da velocidade de maturação de maçãs na planta e úteis para prever a data de colheita, especialmente para frutos destinados a armazenagem em AC por longos períodos (ARGENTA et al.,
1995). Análises de regressão indicaram que a taxa de perda de firmeza em função da data de colheita, para frutos analisados no dia seguinte à colheita, foi de 4,2 e 3,4 N por semana nos pomares MKM9 e M9, respectivamente (Tabela1). Esses valores são menores do que aquele observado para maçãs 'Gala' (5,7 N por semana) e ligeiramente maior ou menor, dependendo do pomar, àquele observado para maçãs 'Fuji' (3,7 N por semana), produzidas na mesma região de Fraiburgo-SC (ARGENTA et al., 1995). Plotto et al. (1995) verificaram taxas de perda de firmeza de polpa de 6,7 N e 1,6 N por semana para maçãs 'Gala' e 'Fuji', respectivamente, produzidas em Washington, EUA. Isso significa que a maturação de maçãs 'Daiane' é ligeiramente mais lenta que a de maçãs 'Gala' e mais rápida que a de maçãs 'Fuji'. As taxas de perda de firmeza da polpa durante a maturação de maçãs são maiores quando crescidas sobre porta-enxertos anões, como M-9, do que sobre porta-enxertos vigorosos, como Marubakaido (BARDEN; MARINI 1992). Isso não foi observado neste estudo, provavelmente, devido à aplicação précolheita de AVG nas plantas sobre M-9.

A taxa de perda da firmeza em função da data de colheita, para frutos analisados após a armazenagem, foi semelhante àquela observada na colheita para o pomar MKM9, e ligeiramente maior que aquela observada na colheita para o pomar M9 (Figura 2, Tabela 1). Esses resultados indicam que o efeito do ponto de colheita sobre a perda de firmeza durante a armazenagem variou entre os pomares: maçãs 'Daiane' do pomar MKM9, colhidas precocemente, apresentaram perda de firmeza, durante a armazenagem, semelhante àquelas colhidas tardiamente, enquanto maçãs 'Daiane' no pomar M9, colhidas precocemente, apresentaram perda de firmeza, durante a armazenagem, menor que aquelas colhidas tardiamente. Por exemplo, maçãs 'Daiane' do pomar MKM9, colhidas entre 112 e 149 DAPF, perderam aproximadamente 16 e $15 \mathrm{~N}$, respectivamente, durante os 240 dias a $0,7^{\circ} \mathrm{C}$ mais 7 dias a $23^{\circ} \mathrm{C}$ (Figura 2). Por outro lado, maçãs 'Daiane' do pomar M9, colhidas entre $112 \mathrm{e}$ 149 DAPF, perderam aproximadamente 14 e $16 \mathrm{~N}$, respectivamente, durante os 240 dias a $0,7^{\circ} \mathrm{C}$ mais 7 dias a $23^{\circ} \mathrm{C}$ (Figura 2).Os dados do presente estudo não permitem inferir o quanto essa diferença entre os dois pomares se deve ao efeito do porta-enxerto ou do tratamento com AVG.

Pesquisas indicam que maçãs com firmeza da polpa inferior a $53 \mathrm{~N}$ são consideradas farináceas, com suculência e crocância muito baixas, e normalmente rejeitadas pelos consumidores (HARKER et al., 2002). Normas legais impedem o despacho e a 
comercialização de maçãs com firmeza da polpa inferior a $50 \mathrm{~N}$ em alguns países como EUA (WASHINGTON, 1999). Essa norma tem sido informalmente usada como referência para estimar o ponto crítico de venda nos principais parques de armazenagem e de empacotamento de maçãs no Brasil.

Maçãs 'Daiane' de ambos os pomares, analisadas no dia seguinte à colheita, apresentaram firmeza da polpa superior a $53 \mathrm{~N}$, independentemente da data de colheita (Figura 2), indicando que poderiam ser colhidas até $149 \mathrm{DAPF}$, se destinadas ao comércio imediatamente após a colheita. No entanto, maçãs de ambos os pomares apresentaram firmeza da polpa inferior a $53 \mathrm{~N}$, após a armazenagem por até 240 dias em AC, quando colhidas de 136 a 149 DAPF. Assim, considerando o ponto crítico de venda, o período ideal de colheita de maçãs 'Daiane' destinada a longos períodos de armazenagem terminou aos $136 \mathrm{DAPF}$, para ambos os pomares. Assim, apesar de os frutos do pomar MKM9 colhidos tardiamente apresentarem taxa de perda de firmeza, durante a armazenagem, semelhante à de frutos colhidos precocemente, aqueles apresentaram menor potencial de armazenagem por atingirem firmeza de polpa crítica antes desses colhidos precocemente.

Aspectos da aparência, incluindo a coloração, ainda são os atributos de qualidade mais percebidos pelos consumidores e que mais influenciam na primeira compra de frutos, embora o contínuo retorno à compra de tais frutos seja determinado pela qualidade sensorial (HARKER et al., 2003). Maçãs do pomar MKM9, colhidas entre 143 e 149 DAPF, apresentaram qualidade sensorial mínima, menor que aquelas colhidas de 113; a $136 \mathrm{DAPF}$, após o armazenamento por 180 dias sob AC, e menor que aquelas colhidas aos 113, 121 e 136 DAPF, após o armazenamento por 240 dias sob AC (Figura 4). Assim, considerando a qualidade sensorial, o período ideal de colheita de maçãs 'Daiane' destinadas a armazenagem não deveria estender-se além de 136 DAPF

Por outro lado, considerando-se a intensidade da coloração vermelha na epiderme, maçãs 'Daiane' apresentaram máxima qualidade quando colhidas entre 143 e 149 DAPF (Figura 2). Normas legais definem que lotes de maçãs classificados como Categoria 1 (CAT 1) devem apresentar 100\% das maçãs com mais de $50 \%$ da superfície avermelhada, enquanto lotes de maçãs classificados como CAT 1 Extra devem apresentar $100 \%$ das maçãs com mais de $75 \%$ da superfície avermelhada (BRASIL, 2006). Considerando-se essa norma legal, as maçãs 'Daiane' deveriam ser colhidas a partir de 121 DAPF, em ambos os pomares, para se produzir pelo menos 50\% (assumindo distribuição normal em torno da média) de frutas CAT 1 (quanto à coloração), as quais possuem maior valor comercial agregado (Figura 3). Pelo menos 50\% das maçãs 'Daiane' do pomar MKM9 poderiam ser classificados como CAT 1 Extra (quanto à coloração), se colhidas a partir de 136 DAPF (assumindo distribuição normal em torno da média).

Medidas de massa indicam que maçãs 'Daiane' cresceram aproximadamente $13 \%$ no pomar MKM9 e 18\% no pomar M9, durante os 35 dias de avaliação (Figura 2), confirmando que a colheita de maçãs tardiamente permite aumento da produtividade (LITTLE; HOLMES, 2000; WATKINS, 2003). No entanto, análises da qualidade após a armazenagem indicam que maçãs 'Daiane' colhidas aos 149 DAPF, no pomar MKM9, apresentam maior risco de desenvolverem rachadura senescente (após 240 dias em AC) e escurecimento pistilar (após 180 dias em AC), em relação aos frutos colhidos de 113 a 136 DAPF (Tabela 2). A incidência de rachadura senescente implica menor rendimento de empacotamento (produtividade) após a armazenagem. Argenta e Mondardo (1994), Ploto et al. (1995) e Steffens et al. (2005) também verificaram o aumento no desenvolvimento de rachadura senescente em maçãs colhidas tardiamente.

A AT diminuiu acentuadamente a partir de 129 DAPF, enquanto os teores de SS aumentaram continuamente em ambos os pomares, durante a maturação (Figura 3). Esses efeitos de data de colheita sobre os teores de AT e SS foram menores ou não existiram nos frutos analisados após a armazenagem. $\mathrm{Na}$ colheita, as relações SS/AT dos frutos colhidos entre 136 e 149 DAPF foram significativamente maiores que aquelas dos frutos colhidos entre $113 \mathrm{e}$ 129 DAPF, em ambos os pomares. A maior relação SS/AT nos frutos colhidos tardiamente, em relação à dos frutos colhidos precocemente, manteve-se após a armazenagem por 240 dias em AC (Figura 3). Altas relações SS/AT observadas após a armazenagem poderiam estar relacionadas, em parte, aos menores índices de qualidade sensorial identificados para frutos do pomar MKM9 colhidos tardiamente. De acordo com Harker et al. (2008), o conteúdo dos SS e a AT podem definir a qualidade de algumas cultivares específicas de maçãs. Na colheita, a relação SS/AT variou de 33 a 50 no pomar MKM9 e de 35 a 52 no pomar M9. Estas relações SS/AT de maçãs 'Daiane' no período de maturação são maiores que aquelas de maçãs 'Gala' (23 a 29), 'Golden Delícious' (22 a $25,5)$ e 'Fuji' (31 a 37) produzidas na mesma região (ARGENTA et al., 1995). 
O distúrbio caracterizado pelo escurecimento pistilar ocorreu apenas nas maçãs colhidas aos 149 DAPF, no pomar MKM9, sendo a incidência de aproximadamente $7 \%$. Já, o distúrbio rachadura senescente ocorreu apenas nas maçãs colhidas aos 143 DAPF, no pomar M9, e nas maçãs colhidas aos 143 e 149 DAPF, no pomar MKM9, sendo as incidências de aproximadamente $2 \%, 5 \%$ e $15 \%$, respectivamente. A incidência de maçãs com podridões foi inferior a $2 \%$ e não foi afetada significativamente $(\mathrm{p}<0,05 \%)$ pela data de colheita. Esses resultados mostram que maçãs da cultivar Daiane podem desenvolver distúrbios fisiológicos relacionados à senescência quando colhidas tardiamente, assim como ocorre em outras cultivares precoces como a 'Gala' (ARGENTA; MONDARDO, 1994).

Os resultados descritos acima, referentes à produção de etileno na colheita, e a firmeza da polpa, qualidade sensorial após a armazenagem indicam que o período adequado de colheita de maçãs 'Daiane', destinadas à armazenagem em $\mathrm{AC}$, não deve estender-se além de 136 DAPF, em ambos os pomares. Por outro lado, frutos do pomar MKM9 não deveriam ser colhidos antes de $121 \mathrm{DAPF}$, e frutos do pomar M9 não deveriam ser colhidos antes de 129 DAPF, por apresentarem intensidade média de cor vermelha muito próxima ou inferior à intensidade mínima legal para frutos classificados como CAT 1. Maçãs produzidas sobre porta-enxertos anões, como o M-9, normalmente apresentam maior coloração avermelhada que aquelas produzidas sobre portaenxertos vigorosos, como Marubakaido, devido, em grande parte, à maior incidência de radiação solar nas maçãs sobre porta-enxerto anões (FALLAHI, 2012). No presente estudo, o efeito do porta-enxerto anão sobre a coloração da casca não foi observado para maçãs 'Daiane', possivelmente devido ao tratamento das plantas com inibidor da síntese de etileno AVG. Estudos demonstraram que a aplicação pré-colheita de AVG retarda o desenvolvimento de cor vermelha em maçãs (STEFFENS et al., 2006; AMARANTE et al., 2010) pela inibição da síntese de antocianinas (WHALE et al., 2008).

Os resultados do presente estudo permitem sugerir que o período ideal de colheita de maçãs 'Daiane', destinadas a longos períodos de armazenagem em AC, ocorreu entre 121 e 136 DAPF para o pomar MKM9, e entre 129 e 136 DAPF para o pomar M9. No período ideal de colheita, a firmeza da polpa de maçãs 'Daiane' foi menor, e o índice de amido maior, em relação àqueles de maçãs 'Gala' e 'Fuji', ao passo que o teor de SS foi maior em relação àquele de 'Gala' e menor em relação àquele de 'Fuji', produzidas na mesma região (ARGENTA et al., 2010).

O período ideal de colheita de maçãs 'Daiane' ocorreu em datas posteriores às do período ideal de colheita de maçãs 'Gala' (23 dias) e anteriores às do período ideal de colheita de maçãs 'Fuji' (50 dias) (ARGENTA et al., 1995). Nesse sentido, o plantio de novos pomares de maçãs 'Daiane' representa uma estratégia para escalonamento da colheita de maçãs no Brasil. O escalonamento da colheita reduz custos de produção relacionados à colheita e recepção dos frutos nos parques de armazenagem, classificação e empacotamento. O escalonamento da colheita pela diversificação de cultivares também reduz o risco de colheita tardia, após o período ideal, permitindo aumento de produtividade pós-armazenagem associada à redução de perdas por deterioração. 


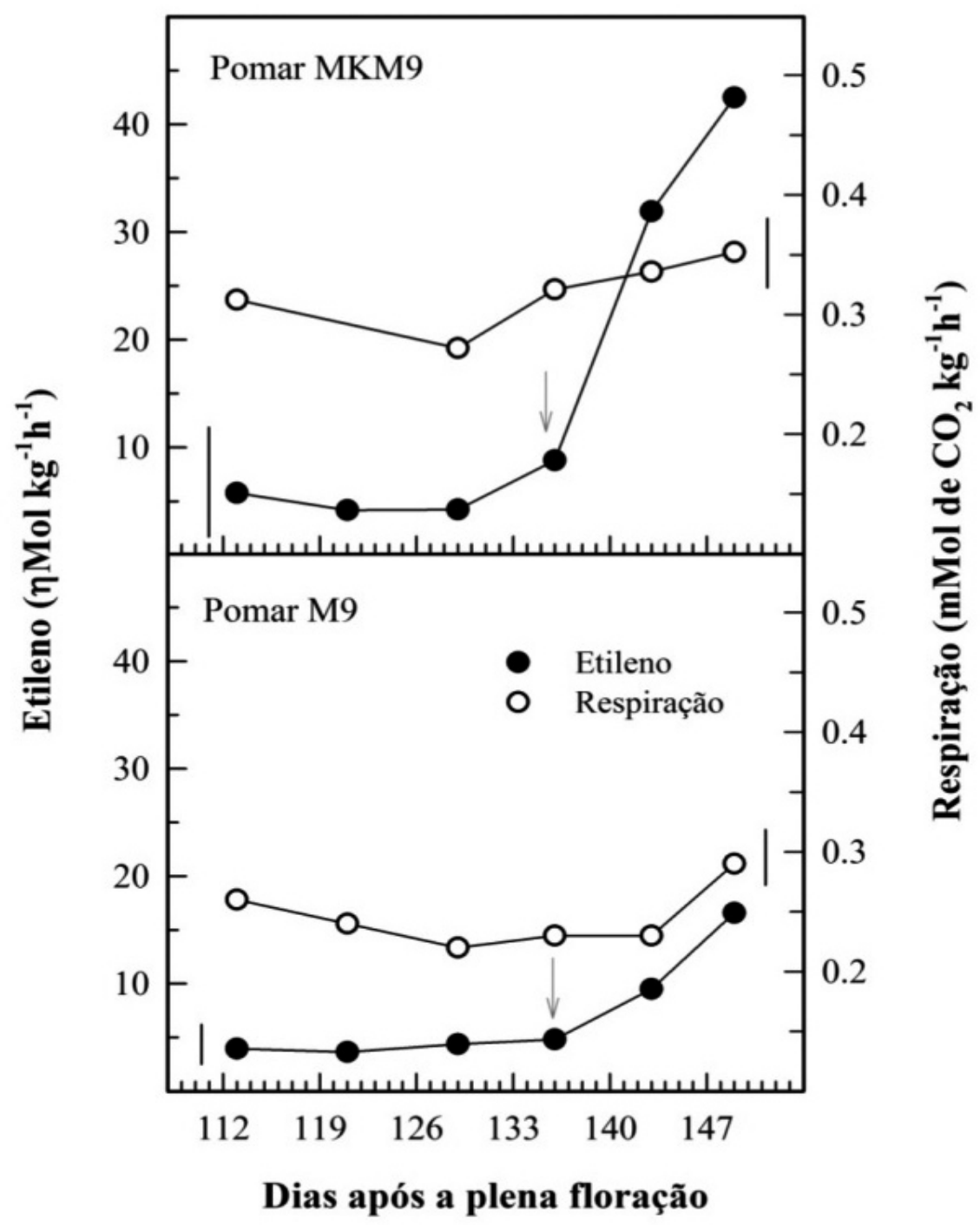

FIGURA 1 - Taxas respiratórias e de produção de etileno de maçãs 'Daiane' na colheita. As barras verticais no interior dos gráficos representam as diferenças mínimas significativas para efeitos de data de colheita $(\mathrm{p}<0,05)$. As setas no interior dos gráficos indicam as datas de colheita a partir das quais houve aumento significativo da taxa de produção de etileno. 


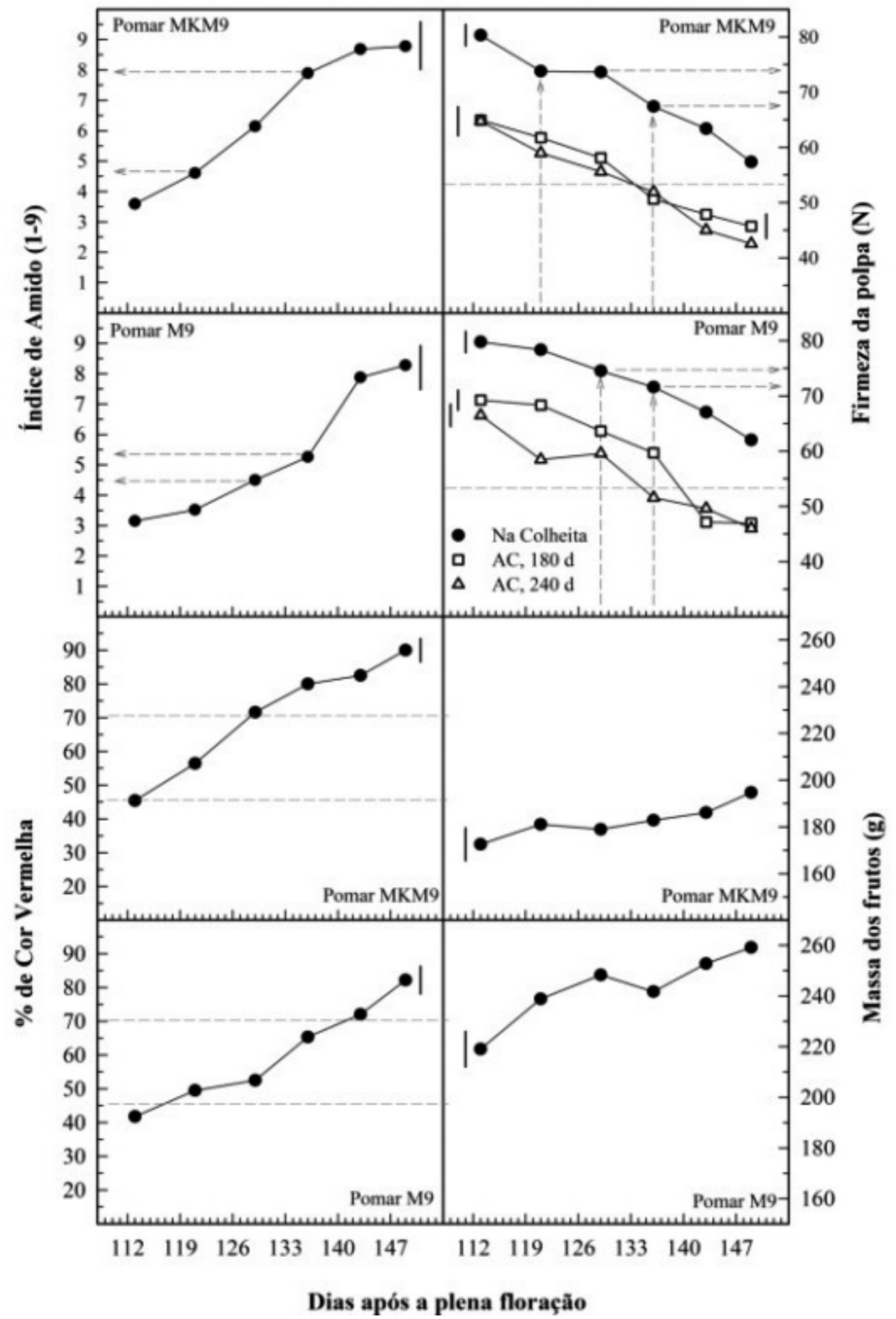

FIGURA 2 - Índices de maturação e qualidade de maçãs 'Daiane' na colheita e após 180 e 240 dias de armazenagem sob atmosfera controlada (AC). As barras verticais no interior dos gráficos representam as diferenças mínimas significativas para efeitos de data de colheita $(p<0,05)$, para cada época de análise dos frutos. As linhas pontilhadas horizontais indicam limite inferior de firmeza da polpa, abaixo do qual as maçãs possuem menor valor e aceitação comercial e de percentagens de cor vermelha para que maçãs sejam classificadas como Categoria $1(50 \%$ de cor vermelha) ou Categoria Extra (75\% de cor vermelha), segundo normas legais brasileiras. As setas horizontais pontilhadas indicam as faixas de índice de amido e firmeza da polpa para o período ideal de colheita (setas verticais pontilhadas). 


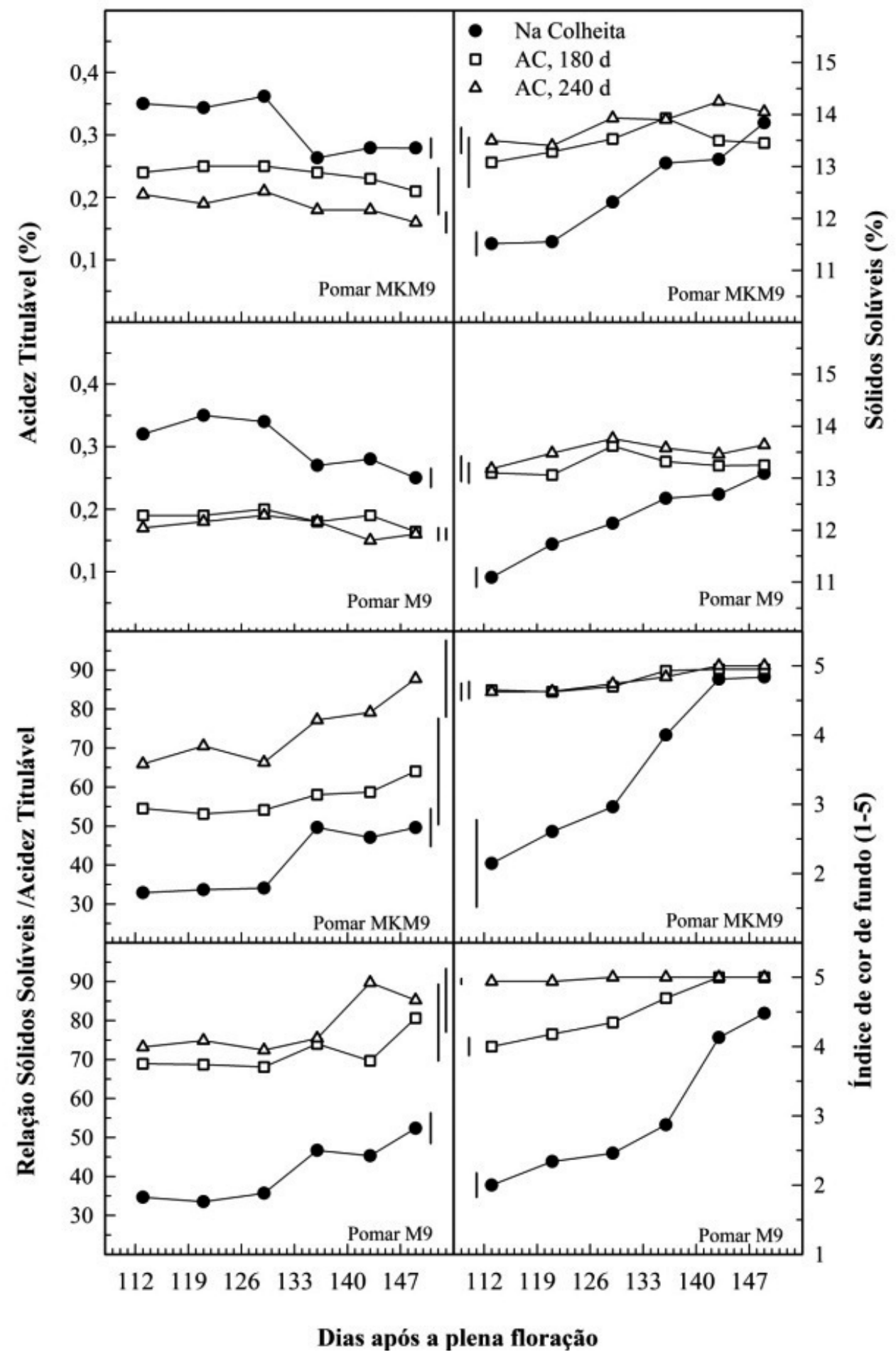

FIGURA 3 - Teores de acidez titulável e de sólidos solúveis, relação sólidos solúveis/acidez titulável e índice de cor de fundo da epiderme de maçãs 'Daiane', na colheita e após 180 e 240 dias de armazenagem sob atmosfera controlada (AC). As barras verticais no interior dos gráficos representam as diferenças mínimas significativas para efeitos de data de colheita $(p<0,05)$, para cada época de análise os frutos. 


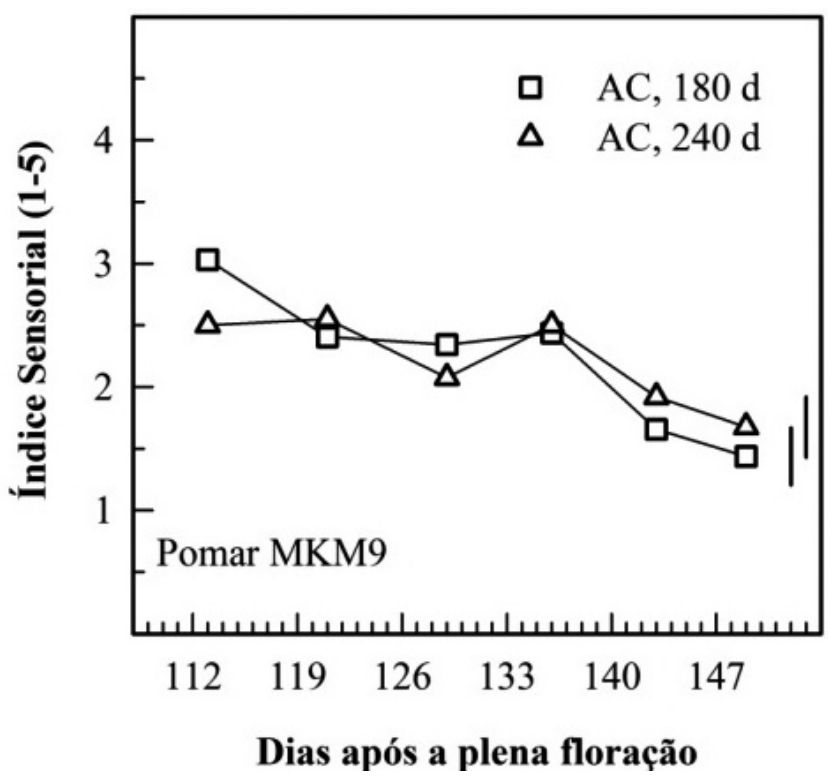

FIGURA 4 - Índice sensorial para o conjunto sabor e textura de maçãs 'Daiane', após 180 e 240 dias de armazenagem sob atmosfera controlada (AC). As barras verticais no interior do gráfico representam as diferenças mínimas significativas para efeitos de data de colheita $(p<0,05)$, para cada período de armazenagem.

TABELA 1 - Taxas de perda da firmeza da polpa (N/semana), estimadas pelas funções de regressão entre data de colheita (x) e firmeza de polpa (y) em maçãs 'Daiane', analisadas na colheita e após 180 e 240 dias de armazenagem sob atmosfera controlada (AC) a $0,7^{\circ} \mathrm{C}$, mais sete dias sob atmosfera do ar (AA) a $23^{\circ} \mathrm{C}$.

\begin{tabular}{cccc}
\hline Pomar & Época de análise & $\begin{array}{c}\text { Função de regressão linear } \\
(\mathrm{y}=\mathrm{bx}+\mathrm{a})^{(1)}\end{array}$ & $\begin{array}{c}\text { Taxa de perda de firmeza } \\
(\mathrm{N} / \text { semana })\end{array}$ \\
\hline \multirow{2}{*}{ MKM9 } & Na colheita & $\mathrm{y}=-0,5971 \mathrm{x}+148,01$ & 4,2 \\
& 180 d AC + 7 d AA & $\mathrm{y}=-0,5744 \mathrm{x}+130,55$ & 4,0 \\
& $240 \mathrm{~d}$ AC $+7 \mathrm{~d}$ AA & $\mathrm{y}=-0,6176 \mathrm{x}+134,55$ & 4,3 \\
& & & 3,4 \\
M9 & Na colheita & $\mathrm{y}=-0,4915 \mathrm{x}+136,38$ & 4,9 \\
& 180 d AC + 7 d AA & $\mathrm{y}=-0,7015 \mathrm{x}+151,64$ & 3,8 \\
\hline
\end{tabular}

${ }^{(1)}$ Significativo a $0,001 \%$ de probabilidade, para as seis equações.

\section{CONCLUSÕES}

1- O período ideal de colheita de maçãs 'Daiane', destinadas a longos períodos de armazenagem, ocorre entre 121 e 136 dias após a plena floração (DAPF) em plantas sobre portaenxerto Marubakaido com filtro M-9, e entre 129 e 136 DAPF em plantas sobre porta-enxerto M-9 e tratadas com aminoetoxivinilglicina (AVG).
2- A firmeza da polpa, os teores de sólidos solúveis e de acidez titulável, e os índices de amido e de cor de fundo da epiderme, relativos ao período ideal de colheita de maçãs 'Daiane', variam de 74 a $67,4 \mathrm{~N}, 11,5$ a $13 \%, 0,34$ a $0,26 \%, 4,6$ a 7,9 e 2,6 a 4,0, respectivamente, para macieiras sobre portaenxerto Marubakaido com filtro M-9, e 74,5 a 71,5 $\mathrm{N}, 12,1$ a $12,6 \%, 0,34$ a $0,27 \%, 4,5$ a $5,2,2,5$ a 2,9 , respectivamente, para macieiras sobre porta-enxerto M-9 e tratadas com AVG. 


\section{AGRADECIMENTOS}

À FAPESC e à FINEP, pelo apoio financeiro, e a Karyne Betinelli e Cleiton de Souza, pela colaboração na execução do projeto.

\section{REFERÊNCIAS}

AMARANTE, C.V.T.; STEFFENS, C.A.; BLUM, L.E.B. Coloração do fruto, distúrbios fisiológicos e doenças em maçãs 'Gala' e 'Fuji' pulverizadas com aminoetoxivinilglicina. Revista Brasileira de Fruticultura, Jaboticabal, v.32, n.1, p.9-18, 2010.

ARGENTA, L.C. Concentração de etileno interno e maturação de maçãs cvs. Gala, Golden Delicious e Fuji. Revista Brasileira de Fruticultura, Jaboticabal, v.15, n.1, p.125-132, 1993.

ARGENTA, L.C.; BENDER, R.J.; KREUZ, C.L.; MONDARDO, M. Padrões de maturação e índices de colheita de maçãs cvs. Gala, Golden Delicious e Fuji. Pesquisa Agropecuária Brasileira, Brasília, v.30, n.10, p.1.259-1.266, 1995.

ARGENTA, L.C.; MONDARDO, M. Maturação na colheita e qualidade de maçãs 'Gala' após a armazenagem. Revista Brasileira de Fisiologia Vegetal, São Carlos, v.6, n.2, p.135-140, 1994.

ARGENTA, L.C.; VIEIRA, M.J.; SCOLARO, A.M. Validação de catálogos de cores como indicadores do estádio de maturação e do ponto de colheita de maçã. Revista Agropecuária Catarinense, Florianópolis, v.23, n.3, p.71-77, 2010.

BRASIL. Ministério da Agricultura, Pecuária e Abastecimento. Regulamento técnico de identidade e qualidade da maçã. Brasília, 2006. 9 p. (Instrução Normativa, 5).

BARDEN, J.A.; MARINI, M.E. Maturity and quality of 'Delicious' apples as influenced by rootstock. Journal American Society Horticultural Science, Salt Lake City, v.117, n.4, p.547-550, 1992.

CHAVES, J.B.P.; SPROESSER, R.L. Práticas de laboratório de análise sensorial de alimentos e bebidas. Viçosa: UFV, 2005. 81p.
DE CASTRO, E.; BIASI, W.; MITCHAM, E.J. Quality of 'Pink Lady'apples in relation to maturity at harvest, pre-storage treatments, and controlled atmosphere during storage. Horticultural Science, Alexandria, v.42, n.3, p.605-610, 2007.

DENARDI, F.; CAMILO, A.P. Daiane: Nova cultivar de macieira para colheita em março. Revista Agropecuária Catarinense, Florianópolis, v.11, n.3, p.6-8, 1998 .

FALLAHI, E. Influence of rootstock and irrigation methods on water use, mineral nutrition, growth, fruit yield, and quality in 'Gala' apple. HortTechnology, Alexandria, v.22, n.6, p.731-737, 2012.

FIORAVANÇO, J.C.; DENARDI, F.; CZERMAINSKI, A.B.C.; KVITSCHAL, M.V. Avaliação da cultivar de macieira Daiane em Vacaria-RS. Bento Gonçalves: Embrapa Uva e Vinho, 2011. 8p. (Comunicado Técnico, 109).

HARKER, F.R.; GUNSON, F.A.; JAEGER, S.R. The case for fruit quality: an interpretive review of consumer attitudes, and preferences for apples. Postharvest Biology and Technology, Amsterdam, v.28, n.1, p.333-347, 2003.

HARKER, F.R.; KUPFERMAN, E.M.; MARIN, A.B.; GUNSON, F.A.; TRIGGS, C.M. Eating quality standards for apples based on consumer preferences. Postharvest Biology and Technology, Amsterdam, v.50, n.1, p.70-78, 2008.

HARKER, F.R.; MAINDONALD, J.; MURRAY, S.H.; GUNSON, F.A.; HALLETT, I.C.; WALKER, S.B. Sensory interpretation of instrumental measurements 1: texture of apple fruit. Postharvest Biology and Technology, Amsterdam, v.24, n.1, p.225-239, 2002.

LITTLE, C.R.; HOLMES, R.J. Harvest maturity. In: LITTLE, C.R.; HOLMES, R.J. Storage technology for apples and pears. Knoxfield: Department of Natural Resources and Environment, 2000. p.112152.

PLOTTO, A.; AZARENKO, N.;MATTHEIS, J.P.; McDANIEL, M. 'Gala', 'Braeburn' and 'Fuji' apples: maturity indices and quality after storage. Fruit Varieties Journal, University Park, v.49, n.3, p.133-142, 1995. 
STEFFENS, C.A.; GIEHL, R.F.H.; BRACKMANN, A. Maçã 'Gala' armazenada em atmosfera controlada e tratada com aminoetoxivinilglicina e ethephon. Pesquisa Agropecuária Brasileira, Brasília, v.40, n.9, p.837-843, 2005.

STEFFENS, C.A.; GUARIENTI, A.J.W.; STORCK, L.; BRACKMANN, A. Maturação da maçã 'Gala' com a aplicação pré-colheita de aminoetoxivinilglicina e ethephon. Ciência Rural, Santa Maria, v.36, n.2, p.434-440, 2006.

WASHINGTON STATE LEGISLATURE. Washington inspection procedures. Washington Agriculture Code. Olympia, 1999. Disponível em: <http://apps.leg.wa.gov/WAC/default. aspx?cite=16-403-142. $>$. Acesso em: 17 out. 2012.

WATKINS, C.B. Principal and practices of postharvest handling and stress. In: FERREE, D.C.; WARRINGTON, I.J. Apples: botany, production and uses. Wallingford: CABI Publishing, 2003. p.585-614.
WATKINS, C.B.; ERKAN, M.; NOCK, J.F.; IUNGERMAN, K.A.; BEAUBRY, R.M.; MORAN, R.E. Harvest data effects on maturity, quality, and storage disorders of 'Honeycrisp' apples. HortScience, Salt Lake, v.40, n.1, p.164-169, 2005.

WATKINS, C.B.; JAMES, H.; NOCK, J.F.R.; OAKES, R.L. Preharvest application of 1-methylcyclopropene (1-MCP) to control fruit drop of apples, and its effects on postharvest quality. Acta Horticulturae, Wageningen, n.877, v.1, p.365-374, 2010.

WHALE, S.K.; SINGH, Z.; BEHBOUDIAN, M.H.; JANES, J.; DHALIWAL, S.S. Fruit quality in 'Cripp's Pink' apple, especially colour, as affected by preharvest sprays of aminoethoxyvinylglycine and ethephon. Scientia Horticulturae, Amsterdam, v.115, n.4, p.342-351, 2008. 